Revue d'histoire de l'Amérique française

REYUE D.HISTOIRE DE L'AMÉRIQUE FRANÇAISE

\title{
SARRA-BOURNET, Michel, L'Affaire Roncarelli : Duplessis contre les Témoins de Jéhovah. Québec, Institut québécois de recherche sur la culture, 1986. 196 p.
}

\section{Richard Jones}

Volume 40, numéro 3, hiver 1987

URI : https://id.erudit.org/iderudit/304476ar

DOI : https://doi.org/10.7202/304476ar

Aller au sommaire du numéro

Éditeur(s)

Institut d'histoire de l'Amérique française

ISSN

0035-2357 (imprimé)

1492-1383 (numérique)

Découvrir la revue

Citer ce compte rendu

Jones, R. (1987). Compte rendu de [SARRA-BOURNET, Michel, L'Affaire

Roncarelli : Duplessis contre les Témoins de Jéhovah. Québec, Institut québécois

de recherche sur la culture, 1986. 196 p.] Revue d'histoire de l'Amérique

française, 40(3), 444-445. https://doi.org/10.7202/304476ar d'utilisation que vous pouvez consulter en ligne.

https://apropos.erudit.org/fr/usagers/politique-dutilisation/ 
SARRA-BOURNET, Michel, L'Affaire Roncarelli: Duplessis contre les Témoins de Jéhovah. Québec, Institut québécois de recherche sur la culture, $1986.196 \mathrm{p}$.

L'auteur de cet ouvrage s'est mérité le Prix Edmond-de-Nevers décerné annuellement par l'IQRC pour couronner la meilleure thèse de maîtrise portant sur la culture, quelle que soit la discipline concernée. Heureuse initiative, il est à espérer que le prix ne connaîtra pas le sort que le gouvernement provincial semble vouloir réserver à l'IQRC dans le cadre des compressions budgétaires.

Pour réaliser cette recherche, Sarra-Bournet a eu recours à une grande diversité de sources comprenant thèses, études, articles, périodiques, brochures et documents gouvernementaux. Il n'a pu consulter, malheureusement, le fonds Maurice-Duplessis, fermé jusqu'en l'an 2000. L'auteur a aussi interviewé dix Québécois quant à leur perception des Témoins de Jéhovah. Pourtant l'échantillon retenu n'a rien de scientifique. En plus de comprendre un monsieur «X», cette courte liste inclut une dénommée «A. Désilets», de Sherbrooke, que l'auteur remercie spécialement pour ses «judicieux conseils». Certes, on devine mal de qui il pourrait s'agir, la seule précision donnée étant que cette personne est «née entre 1909 et 1949»!

Le Québec n'était pas seul à réprimer et à persécuter les Témoins de Jéhovah. Le gouvernement canadien mit la secte hors la loi au cours de la deuxième guerre. Aux États-Unis, des centaines de procès pour sédition et pour refus de faire le service militaire furent intentés contre les membres de ce groupe. Dans l'Allemagne de Hitler, un grand nombre d'entre eux ont fini leurs jours dans les camps de concentration. Et même aujourd'hui, dans le bloc communiste, les Témoins ne bénéficient guère de la liberté religieuse. Dans la plupart des pays, les catholiques se trouvaient à l'avant-garde des attaquants. Rien de surprenant à cela car chacun de ces deux groupes, convaincu de détenir la vérité et souhaitant la propager, était l'ennemi juré de l'autre.

En introduction, l'auteur présente les Témoins, leurs croyances, leur histoire. Puis, dans un premier chapitre, il décrit la «guerre sans merci» qui leur fut livrée dans le Québec duplessiste. Le chapitre suivant fait état des procédures judiciaires en rapport non seulement avec l'affaire Roncarelli mais aussi avec d'autres cas touchant la réglementation municipale, le domaine de l'éducation, etc. Enfin, l'auteur présente les réactions suscitées par l'affaire.

Frank Roncarelli fut un restaurateur montréalais. Il déposa des dizaines de milliers de dollars en caution pour permettre à ses co-religionnaires de retrouver leur liberté. Après l'avoir averti de «cesser d'encourager une entreprise séditieuse», Duplessis intervint, «à titre de procureur général et de premier ministre», pour faire retirer à Roncarelli le permis de vente de «liqueurs alcooliques» qu'il détenait de l'organisme qu'on dénommait alors la «Commission des liqueurs du Québec». Roncarelli perdit donc son gagne-pain. Duplessis justifia son geste en affirmant que le permis était un privilège accordé à «des gens de bonne conduite et soumis aux lois» alors que Roncarelli utilisait l'argent qu'il gagnait à vendre des boissons alcoolisées pour défendre des "zélateurs d'une philosophie subversive», des gens de même acabit que «les communistes et les nazis». (Y eut-il réellement des sympathisants de l'extrême-droite qui eurent maille à partir avec Duplessis?) Roncarelli intenta des poursuites contre Duplessis personnellement en réclamant des dommages-inté- 
rêts. Enfin, en 1959, treize ans après le début de l'affaire - que les roues de la justice tournent donc lentement! - la Cour suprême du Canada lui donna raison estimant que Duplessis avait outrepassé son mandat et commis un abus de pouvoir. Compte tenu des véritables pertes de Roncarelli et de ses dépenses légales, la compensation accordée n'était que symbolique. De toute façon, c'est l'Union Nationale qui a avancé les fonds que Duplessis dut verser.

L'auteur présente dans un style vivant l'affaire Roncarelli et, plus généralement, la lutte contre les Témoins de Jéhovah au Québec. Dans son dernier chapitre, cependant, il souhaite innover en tentant de démolir le mythe d'un Québec monolithique. Malheureusement, il réussit plutôt à démontrer l'hypothèse contraire, du moins en ce qui concerne les Témoins. Il est vrai que $L e$ Devoir a fini par désapprouver le comportement de Duplessis à l'égard de cette secte dans un texte qui date de 1959; mais à cette époque quel geste du chef unioniste ce journal approuvait-il? Il est vrai aussi que Thérèse Casgrain, le pasteur Claude de Mestral, Adélard Godbout, et Cité libre ont de leur côté défendu les Témoins. Mais c'est bien peu de gens. L'élite canadienne-française approuvait Duplessis. La grande majorité des groupes de pression étaient d'accord avec lui. En outre, soutient l'auteur, «il y a tout lieu de croire que ces opinions... étaient partagées par l'ensemble de la population, particulièrement ceux qui étaient régulièrement sollicités par les Témoins de Jéhovah». Ou encore, comme il l'écrit: «Toute initiative dans le but d'éliminer [les Témoins de Jéhovah] recevait l'assentiment de la population en général.» Voilà donc clairement démontrée l'existence d'une quasi unanimité chez les Francophones.

En ce qui concerne les Anglophones du Québec, beaucoup d'entre eux, du moins ceux qui écrivaient dans le Montreal Star ou qui enseignaient à l'Université McGill, manifestaient de la sympathie pour les Témoins. L'auteur estime que ces gens étaient «attachés aux libertés civiles». Mais que se seraitil passé si des Francophones, habitant certaines villes québécoises à majorité anglaise dont les administrations municipales ne fonctionnaient qu'en anglais, s'étaient mis à réclamer le bilinguisme? Ces mêmes Anglophones auraient-ils alors manifesté un attachement aussi vigoureux pour les libertés civiles à caractère linguistique? En effet, la tolérance n'est peut-être pas une affaire de race.

Quelques conclusions discutables mises à part, l'auteur réussit à bien peindre un chapitre plutôt sombre de notre histoire. Le lecteur consultera cet ouvrage avec plaisir. 